\title{
Reversible Electroporation Study of Realistic Normal and Cancerous Cervical Cells Model Using Avalanche Transistor Based Nanopulse Generator
}

Mayank Kumar ( $\nabla$ rss2018501@iiita.ac.in )

Indian Institute of Information Technology Allahabad

Ashutosh Mishra

Indian Institute of Information Technology Allahabad

\section{Research Article}

Keywords: Reversible electroporation, realistic, cervical cells

Posted Date: March 5th, 2021

DOI: https://doi.org/10.21203/rs.3.rs-276016/v1

License: (c) (1) This work is licensed under a Creative Commons Attribution 4.0 International License.

Read Full License 


\title{
Reversible electroporation study of realistic normal and cancerous cervical cells model using avalanche transistor based nanopulse generator
}

\author{
Mayank Kumar ${ }^{1}$ and Ashutosh Mishra ${ }^{2}$ \\ 1,2Department of Applied Sciences(Biomedical Engineering),Indian Institute of Information Technology \\ Allahabad,Prayagraj,India \\ *rss2018501@iiita.ac.in \\ +am@iiita.ac.in
}

\begin{abstract}
In this paper, we study the reversible electroporation process on the normal and cancerous cervical cell. The 2D contour of the cervical cells is extracted using image processing techniques from the Pap smear image. The conductivity change in the cancer cell model has been used to differentiate the effects of the high-frequency electric field on normal and cancerous cells. The cells modulate themselves when this high-frequency pulse is applied based on the Debye relaxation relation. In order to computationally visualize the effects of the electroporation on the cell membrane Smoluchowski equation calculates the number of pores generated and Maxwell equations are used to determine the Transmembrane potential generated on the membrane of the cervical cell. The results produced demonstrates that this mathematical model perfectly describes the numerical tool to study the normal cells and cancerous cells under the electric field. The electric field is provided with the help of a realistic pulse generator which is designed on the principle of Marx circuit and avalanche transistor-based operations to produce a Gaussian pulse. The paper here use strength duration curve to differentiate the electric field and time in nanoseconds required to electroporate normal and cancerous cells.
\end{abstract}

\section{Introduction}

The cervical cancer is the most common occurrence in women as per data given ${ }^{1}$. The conventional Pap smear test or liquid cytology-based test is performed which is expensive and the false rate is high around 40 . Various methods have been proposed to detect cervical cancer ${ }^{2}$. The reversible electroporation method can be adopted as it can easily be used for drug delivery and dyes can be easily transported to the cytoplasmic area by the formation of pores in the cell membrane if a sufficient electric field is applied for nanosecond time as it generates a transmembrane potential that is around $1 \mathrm{~V}$ to $1.5 \mathrm{~V}^{3-8}$. The mathematical model has been proposed for the study of pore formation and the amount of trans-membrane potential generated during electroporation ${ }^{7}$. The microdosimetry study has been used to generate models that are reliable for quantitative analysis of pores and the transmembrane potential induced in the cells ${ }^{9}$. Thus, these models can give a clear indication as to how much amplitude, waveform, and frequency content must be applied to design and optimize the pulse generator for electroporation studies $^{9}$. The human neuroblastoma cells geometric model has been extracted for microdosimetry work in earlier literature ${ }^{10}$. The image processing techniques have also been used to accurately extract the contour of the cells in $2 \mathrm{D}^{10}$. Another work has been published to accomplish this task by using the parametric curve such as the Supergielis formula to generate the geometry that nears the irregular cell ${ }^{7}$ of the Jukart cells. This formula has also been used in numerous literature for replicating muscle cells as well as Red blood cells ${ }^{11}$. Efforts have also been made to generate 3D models of the cell ${ }^{12}$. In the case of cervical cells, rectangular parallelopiped geometry has been proposed to carry out the FEM based numerical analysis and was able to give accurate dimensions of the various types of normal cervical cells and their respective stages of cancer cells dimension variations in cytoplasmic as well as in the nucleus region ${ }^{13,14}$. The cervical cancer tissue has been studied for irreversible electroporation process where the conductivity change is represented using the asymmetrical sigmoid Gompertz curve function and experimentally verified. The changes in the conductivity by a factor of 1.8 has been observed ${ }^{15}$. This change in the conductivity of tumor cells in the solution has been also observed using electric conductivity measure using 3T MRI techniques ${ }^{16}$. Most of the literature have demonstrated a change in the conductivity of cancerous cells and the disruption of the cell membrane in cancer cells as a result of electronegativity thus resulting in a reduction of membrane potential ${ }^{17}$. A high concentration of $\mathrm{Na}$ and $\mathrm{Cl}$ is found in the cancer cells ${ }^{19}$. The efficiency of the given numerical model depends on the morphology of the cell introduced in the electroporation area and the electric field pulse also provided ${ }^{5}$. The dispersive and 
nondispersive models are provided to study the effects of electroporation in the earlier studies ${ }^{5}$ but the dispersive model has been found out to have low permittivity at large frequencies hence, more Transmembrane voltage. The comparison between the both has been provided by many earlier works ${ }^{5,7}$ and it has also been found that a low amount of electric field is required by the dispersive model to generate the transmembrane potential. Another major problem is found in the computation as the membrane layer is found to be around $5 \mathrm{~nm}^{5,7}$ thus the concept of the thin layer is used to lower the computational requirement.

\section{Materials and Methods}

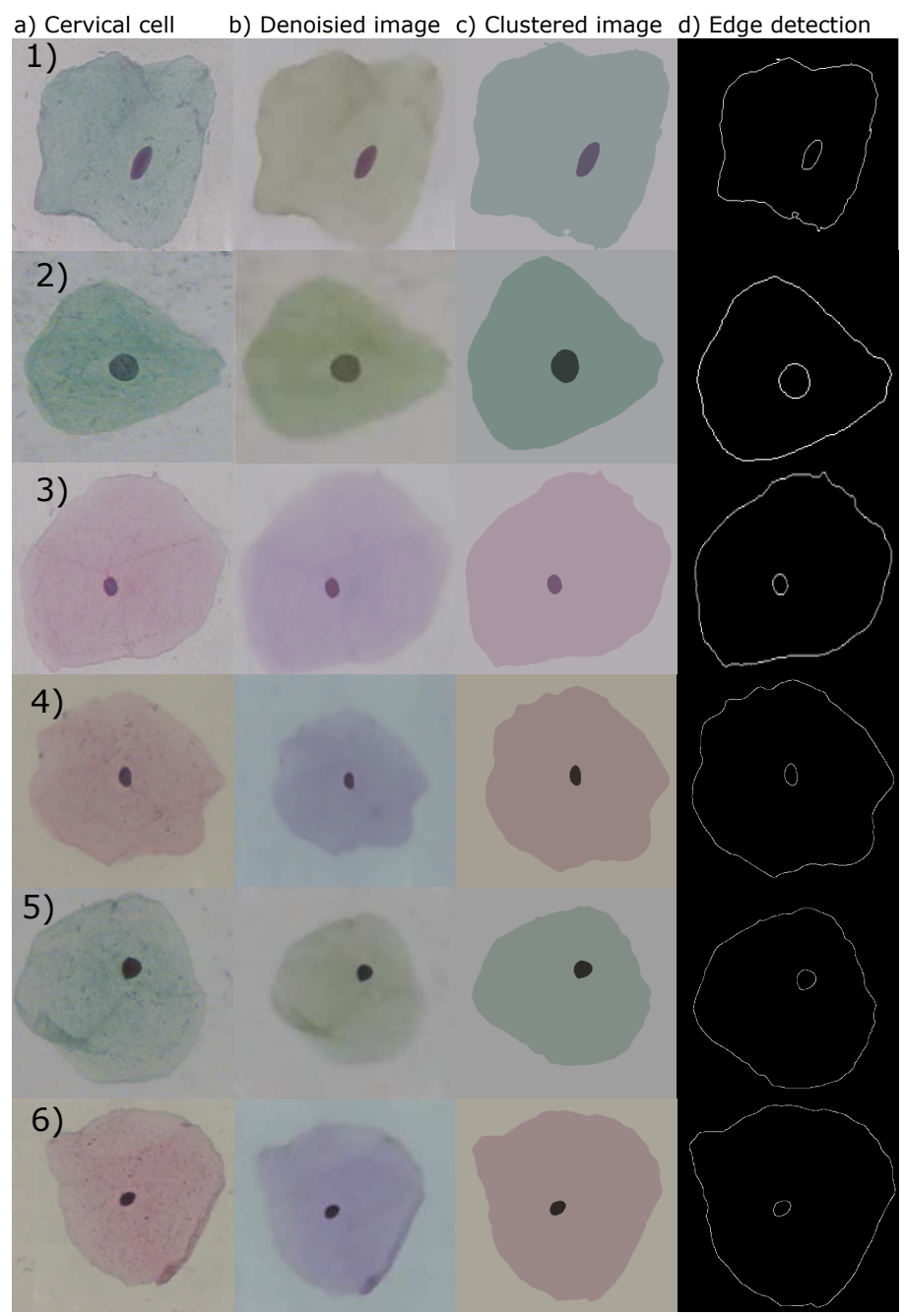

Figure 1. Stage wise contour extraction (a) single cervical cell (1-2) Intermediate cells (3-6) Superficial cell, (b) Denoised image by using image denoising function, (c) K-means clustering performed on the cells, (d) Edge detection and contour extraction using Sobel filter .

\subsection{Extraction of geometry from cervical cell image}

In this method, we use K-clustering and image processing techniques to extract the 2D geometry of the cervical cells mainly superficial and intermediate single pap cells from the image data set as shown in Figure 1. The two-dimensional cells are then converted to three-dimensional cells for further analysis.

\subsubsection{Image acquisition}

The images of the cervical cells are available on the website of MDE-lab, University of the Aegean ${ }^{18}$. The data set consists of 917 single pap cells. The cells of normal and intermediate cervical cells were taken from the data set for the extraction 
of contour using image processing techniques. The data set consists of around 74 normal superficial cells and 70 normal intermediate cells. In this paper, we have randomly selected a few to demonstrate the contour extraction procedure.

\subsubsection{Image denoising}

The presence of noise in the image is the major challenge in the field of image processing. The pap smear images consist of noise hence the quality of the picture is reduced. The denoising method called nonlocal means to suppress the noise in the images. The python 3.7 software was used for processing the image using the Open source computer vision (OpenCV) library. The library has already built-in functions for filtering using a nonlinear filter for denoising colored images. This method removes Gaussian noise from the image due to which the cytoplasmic area in the image gets cleared as the image it is observed having particles resembling Gaussian noise. Thus an image with a well-defined boundary and nucleus can be observed.

\subsubsection{K-means clustering algorithm for cell segmentation}

The K-means clustering perfectly segments the nucleus and the cytoplasmic area from the pap images. The image was segmented into three groups nucleus, cytoplasm, and background using the k-means algorithm. The histogram analysis of the image is done which gives the intensities. The k-clusters centroids were initialized with three centers. Each intensity distance was calculated and shortest distance intensities were clubbed together from the centroids initialized. Then new centers are assigned by calculating the mean of all the members in their respective clusters. Thus repeating the last steps till no change in the image is done.

\subsubsection{Morphological operations for contour detection}

Now the segmented image is binarized ${ }^{20}$. We use MATLAB $2020 \mathrm{~b}$ for this operation and use the inbuilt function of drawing perimeter and getting the contour of the image. We get the respective contours of the image in two-dimensional space. The image is then a vector image, QCAD an open-source is further used for modification of the image. The cervical cell's dimensions are changed by the transformation method and reshaped according to the dimensions of the cell ${ }^{13,14}$. The Table 1 below shows the dimensions of the cell.

Table 1. Cervical cell dimension table

\begin{tabular}{|c|c|c|c|c|}
\hline Cell types & \multicolumn{2}{|c|}{ Cell } & \multicolumn{2}{c|}{ Nucleus } \\
\hline & $\mathrm{X}$ & $\mathrm{Y}$ & $\mathrm{X}$ & $\mathrm{Y}$ \\
\hline Superficial & $66 \mu \mathrm{m}$ & $66 \mu \mathrm{m}$ & $8.4 \mu \mathrm{m}$ & $8.4 \mu \mathrm{m}$ \\
\hline Intermidiate & $52 \mu \mathrm{m}$ & $52 \mu \mathrm{m}$ & $8.6 \mu \mathrm{m}$ & $8.6 \mu \mathrm{m}$ \\
\hline Parabasal & $31 \mu \mathrm{m}$ & $31 \mu \mathrm{m}$ & $8.3 \mu \mathrm{m}$ & $8.3 \mu \mathrm{m}$ \\
\hline Basal & $16 \mu \mathrm{m}$ & $16 \mu \mathrm{m}$ & $9.0 \mu \mathrm{m}$ & $9.7 \mu \mathrm{m}$ \\
\hline
\end{tabular}

\subsection{Geometry model of cervical cell}

The cell model used in earlier studies has regular geometry like a circle or ellipse sometimes a combination of both the geometries. They gave an inaccurate result as they were not close to the representation of the realistic cell geometry. A new method of using the Supergielis formula has been put forward which creates an irregular cell geometry.

$$
\begin{aligned}
& r=\widehat{r} \sqrt{x^{2}+y^{2}}, x=k_{x} R(\theta) \cos \theta \text { and } y=k_{y} R(\theta) \sin \theta \\
& R(\theta)=\left(\left|\frac{\cos \left(m_{1} \theta / 4\right)}{a_{1}}\right|^{n_{1}}+\left|\frac{\sin \left(m_{2} \theta / 4\right)}{a_{2}}\right|^{n_{2}}\right)^{-\frac{1}{b_{1}}}
\end{aligned}
$$

Where $m_{1}=m_{2}=3, b_{1}=30, n_{1}=n_{2}=15, \theta \in[-\pi / 2, \pi / 2]$ are the parameters to create the required to create the geometry of superficial cervical cells. The parameters $k_{x}$ and $k_{y}$ are the scaling factors with $a_{1}$ and $a_{2}$ being the positive real numbers. The output of this parametric curve is shown in the Figure 4.

\subsection{Pulse generator based on Avalanche transistor}

\subsubsection{Avalanche transistor}

Avalanche transistor is used for high-speed pulse operation. They have high frequency and low impedance.There are many ordinary transistors available for avalanche operation such as 2N2222,2N5551,2N2396a,2N23907 available for avalanche operation $^{21}$. Zetex has provided for a range of FMMT series avalanche transistors for high voltage operations such as FMMT411, 
FMMT413, FMMT415, and FMMT417. These operate in a very high voltage operation region as the breakdown voltage of these circuits lies in the range of $80 \mathrm{~V}$ to $320 \mathrm{~V}$. These have inbuilt Zener diodes, switches, and inductors for avalanche operation. Together with the Gummel-Poon model they give the respective output in simulation ${ }^{22}$. Hence, it is easy to simulate these circuits as the manufacturers provide the spice model and diode connections but ordinary transistor does not have such components hence the avalanche operation simulation is difficult as the transistors are based on simple Gummel-Poon model. Hence, additional current sources were added to demonstrate the operation ${ }^{23}$. This model perfectly depicted the avalanche operation in the generators. A spice sub-circuit script is written to add the multiplication factor based on avalanche theory. The supply voltage has been considered between the range of $60 \mathrm{~V}$ to $100 \mathrm{~V}$ DC due to the limited operating range of the transistor. The 2N2396a transistors are cheaper easily available and quite frequently used for many transistor applications. There are many avalanche transistors available the selection basis must be the supply voltage available such that the avalanche breakdown occurs. The breakdown is represented by a simple equation $I_{C 1}=M I_{C 1}$ where $\mathrm{M}$ is the multiplication factor represented by equation

$$
\begin{gathered}
M=\frac{1}{1-\left(U_{c b} / U_{b r}\right)^{N}} \\
I_{E X}=I_{c}\left(U_{c b} / U_{b r}\right)^{N}
\end{gathered}
$$

Where $U_{b r}$ represents the breakdown voltage and $\mathrm{N}$ is a constant depends on the $\mathrm{BC}$ junction type and material used. Generally, the value of $\mathrm{N}$ varies between 4 and $6^{23}$.

\subsubsection{Marx generator}

The simulation of the Marx generator is performed in MATLAB Simulink 2020b. In order to perform the transistor 2N2396a spice, a sub-circuit is imported which has been added with current sources as explained earlier. The resistance of $R_{C 1-5}=R_{C_{1-4}^{\prime}}=4.7 \mathrm{k} \Omega$ and $C_{1}$ to $C_{5}=1 n F$ Figure 2 . a) shows the basic operation of the five-stage Marx generator ${ }^{2425}$. The voltage provided by the DC source is less than $V_{c b o}$ which is $60 \mathrm{~V}$. The simulation output of the Marx generator is shown in Figure 2.c) and the output of the digital oscilloscope TDS210 is shown in Figure 2.d) and the terminals are reversed for taking positive output. The output has been reduced using a voltage divider arrangement to get the required output. The load is taken $R_{L}=50 \Omega$. The input trigger is provided using a monostable multivibrator with 555 timer IC and RC differentiator circuit to the transistor $T_{1}$. The hardware prototype is shown in Figure 2.b). The five-stage Marx generator is given by the formula

$$
V_{\text {out }}=N \times V_{c c} \times \frac{R_{L}}{N r+R_{L}}
$$

Where $R_{L}$ is the load and $\mathrm{N}$ is the number of stages of marx generator.The $\mathrm{r}$ represents the internal resistance of the avalanche transistor.

\subsection{Mathematical modeling of cervical cell \\ 2.4.1 Modeling of cervical cell permittivity model}

The Multi-relaxation Debye-based relationship is used to model the cervical cell dielectric properties. The cytoplasm and nucleus of the cervical cells in this study uses a dispersive medium whose dielectric properties has been modeled using a second-order equation ${ }^{5}$.

$$
\begin{aligned}
& \varepsilon(\omega)=\varepsilon_{\infty}+\frac{\Delta \varepsilon_{s}+j_{\omega}\left(\tau_{1} \Delta \varepsilon_{2}+\tau_{2} \Delta \varepsilon_{1}\right)}{1-\omega^{2} \tau_{p}+j \omega \tau_{s}} \\
& \Delta \varepsilon_{s}=\Delta \varepsilon_{1}+\Delta \varepsilon_{2}, \tau_{p}=\tau_{1} \tau_{2}, \tau_{s}=\tau_{1}+\tau_{2}
\end{aligned}
$$

$\varepsilon_{\infty}$ denotes the high frequency permittivity,with $\tau_{1}$ and $\tau_{2}$ are the relaxation time and $\Delta \varepsilon_{1}, \Delta \varepsilon_{2}$ are the relaxation amplitude. The polarization vector $\mathrm{P}$ can be expressed in the second-order differential equation which is known as Debye Dispersion model.In this equation, the polarization $\mathrm{P}$ is expressed as a time-varying model of a homogeneous medium in terms of a time-varying electric field given by:

$$
\begin{aligned}
& \tau_{p} \frac{d^{2} P}{d t^{2}}+\tau_{s} \frac{d P}{d t}+P=k_{2} \frac{d^{2} E}{d t^{2}}+k_{1} \frac{d E}{d t}+k_{0} E \\
& k_{0}=\Delta \varepsilon_{s}+\varepsilon_{\infty}-\varepsilon_{0}, k_{1}=\tau_{1}\left(k_{0}-\Delta \varepsilon_{1}\right)+\tau_{2}\left(k_{0}-\Delta \varepsilon_{2}\right), k_{2}=\tau_{p}\left(k_{0}-\Delta \varepsilon_{2}\right)
\end{aligned}
$$



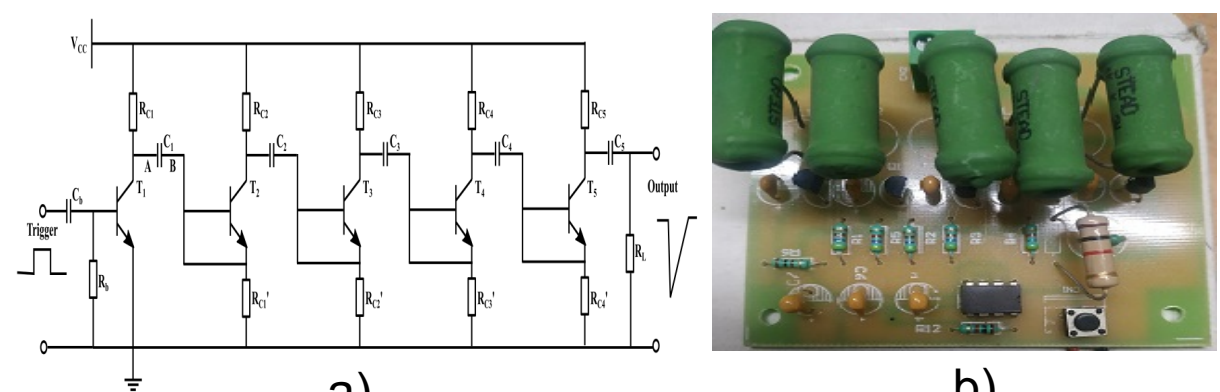

a)

b)
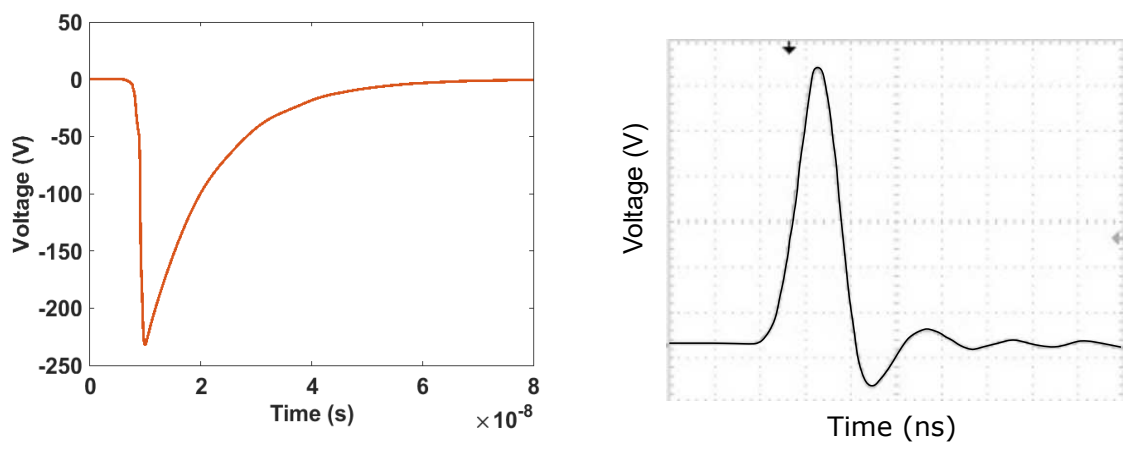

c)

d)

Figure 2. a) Marx Generator schematic diagram ${ }^{25}$, b) Pulse generator hardware, (c) Simulated output of the Marx generator, (d) Output waveform time $\mathrm{X}=20 \mathrm{~ns} / \mathrm{div}$ and voltage $\mathrm{Y}=5 \mathrm{~V} / \mathrm{div}$.

\subsubsection{Pores formation model of cervical cell}

The application of the nano pulse electric field causes pores on the membrane layer which is made up of a bi-lipid layer. The pores generated are assumed to have a radius of $r_{p}=0.8 \mathrm{~nm}$. The dynamics of the creation of pores and resealing is solved by using an asymptotic Smoluchowski's equation:

$$
\frac{\partial N}{\partial t}=\alpha e^{\left.\left(\frac{t m v}{V_{e p}}\right)^{2}\right)}\left[1-\frac{N}{N_{0}} e^{\left(-q\left(\frac{t m v}{V_{e p}}\right)^{2}\right)}\right]
$$

where $\mathrm{N}$ denotes the pore density on the plasma membrane, $\alpha$ and q denotes the electroporation parameters, $V_{e} p$ is the characteristic voltage of electroporation, and $N_{0}$ represents the initial pore density. The electroporation increases the conductivity of the membrane at each time and as the transmembrane potential changes at every step in time the no of pores is updated and the conductivity is different positions in the cell membrane. The average conductivity of the cervical cell membrane at different regions where pores are formed is given by the equation,

$$
\sigma(x, y, t)=\sigma_{0}+\pi \sigma_{p} r_{p} N(x, y, t) K
$$

where

$$
K=\frac{e_{m}^{v}-1}{\frac{w_{0} e^{w} 0-\eta v_{m}}{w_{0}-\eta v_{m}}-\frac{w_{0} e^{w_{0}}+\eta v_{m}}{w_{0}+\eta v_{m}}}
$$

The energy barrier inside the pore is given by $w_{0}$ in equation no. and $\eta$ is the relative entrance length of the pore and the non dimensional transmembrane voltage is expressed as $v_{m}=\frac{q_{e}}{K T} v_{m}$.

\subsubsection{Electromagnetic modelling of the cervical cell}

The electric pulse from the device is applied to the upper and lower copper plates of the simulation model.The electric potential is calculated by solving the Laplace equation :

$$
\nabla . \nabla\left(\sigma+\varepsilon_{0} \frac{\partial \phi}{\partial t}\right)-\frac{\partial \nabla . P}{\partial t}=0
$$


The equation in conjunction with equations $10,12,13$ are used along with equation

$$
E=-\nabla \phi
$$

The Transmembrane potential (TMV) is calculated using a special boundary condition present in COMSOL 5,5 on the cell membrane to reduce computational need which is distributed impedance present in the electric current module of the multi-physics operations. This Distributed impedance boundary layer is used in the parametric curve model and 2D realistic model as the membrane layer is very thin around $5 \mathrm{~nm}$ represented by equation 16 .

$$
\begin{aligned}
& T M V=\phi_{\text {outer }}(x, y, t)-\phi_{\text {inner }}(x, y, t) \\
& n . J=\frac{\sigma_{m}}{d_{m}}\left(V-V_{\text {ref }}\right)+\frac{\varepsilon_{m}}{d_{m}}\left(\frac{\partial V}{\partial t}-\frac{\partial V_{\text {ref }}}{\partial t}\right)
\end{aligned}
$$

$V_{\text {ref }}$ represents the potential on the exterior surface of the cell boundary and $\mathrm{V}$ is the potential on the interior surface of the cell boundary. The $\sigma_{m}, d_{m}$ and $\varepsilon_{m}$ are the conductivity, thickness, and permittivity of the cervical cell membrane. The transmembrane potential is calculated and updated at each step time in the equation 8,10,11,14 and 15. Smoluchowski's equation is solved using the Weak Form Boundary PDE application and the polarization vector equation is solved using the Coefficient form PDE interface. At each time step the $\mathrm{P}$ and the membrane conductivity $\sigma_{m}$ is updated solving the equations $8,10,11,14$ and 15 . The Direct Method is used to solve the 2D model using PARDISO solver. The number of finite elements generated is low for this simplified model than the full model of the membrane.

\section{Discussion}

The method proposed is compared with the actual cervical cell and cancer cervical cell electroporation provided by the literature of irreversible electroporation of cancerous cervical cell ${ }^{15}$. The method uses an actual pulse generated from the avalanche transistor-based pulse generator simulation results rather than an inbuilt function to generate a Gaussian pulse for study. The simulation study using Gaussian pulse has the advantage of reduced artifacts due to the smooth rise and fall time of the pulse. The delay of $5 \mathrm{~ns}$ is given and the pulse width of $40 \mathrm{~ns}$ is added to the electromagnetic model for detailed microdosimetry analysis. The pulse is applied at the top of the electroporation area.The area dimensions are $200 \mathrm{um} \times 200 \mathrm{um}$. The additional $10 \mathrm{um}$ is added to the upper and lower regions of the area. The second step is to extract the $2 \mathrm{D}$ contour of the cervical cell using image processing techniques. The model is then imported to the multiphysics environment. The previous literature has used a rectangular model for Finite element method studies ${ }^{13,14}$. The cervical cells used for the study are superficial and intermediate cells. The paper has also tried to replicate the superficial cell using the Supergielis model. The earlier literature has used the Supergielis formula to replicate smooth muscle cells, RBC, and Jukart cells using this parametric curve. Thus when compared with the realistic model the parametric curve has successfully replicated the superficial cell. Both models have used a dispersive model whose polarization parameters are taken from the literature ${ }^{5}$. The Transmembrane potential formation for the dispersive model is high. The previous literature has shown the differences in the Transmembrane form of the dispersive and the nondispersive models so in this paper only the dispersive model is used for comparison. The contour plots of the 2D cells are shown in the Figure 3. The Transmembrane potential is represented in the contour plot of the figures and pore density formation is shown in Figure 5. The Figure 3.(a) show the elecroporation results under the pulse of the intermediate cells. The Figure 3.(a) and Figure 3.(b) shows the results generated by the cervical cells under the electric field. The results show that the cells easily pass the Transmembrane potential and the pore density needed for electroporation. The Transmembrane rises at the rising edge of the applied pulse input and reaches voltage of $1.5 \mathrm{~V}$. Thus pores formation is possible at this range of Transmembrane voltage. The realistic cell model gives a clear picture of areas of electroporation. The whole Transmembrane voltage was taken at an angle $\theta=90$ where the electric field is directly exposed on the top of the cell membrane. The pores formation when is about $10^{14}$ and above the cells are found to be electroporated. The Figure 4 represents the contour of superficial cell generated by the use of parametric curve and can be easily observed that the TMV and pore density formation validates that the pulse generated can easily electroporate the cells.

The electroporation relative length(EPRL) of the the realistic cell contour and the parametric curve generated shows a great difference.The EPRL is represented by formula

$\operatorname{EPRL}(\%)=($ length of the electroprated region $) \div($ Total perimeter of the plasma memberane $) \times 100$

The EPRL of the parametric curve was found to be $37.2 \%$. Thus the cell morphology plays an important role in the formation of pores and transmembrane generation. A simple parametric curve cannot get the minute changes in morphology that the cells brought from the image processing application can bring out. The orientation of the cervical cells with respect 


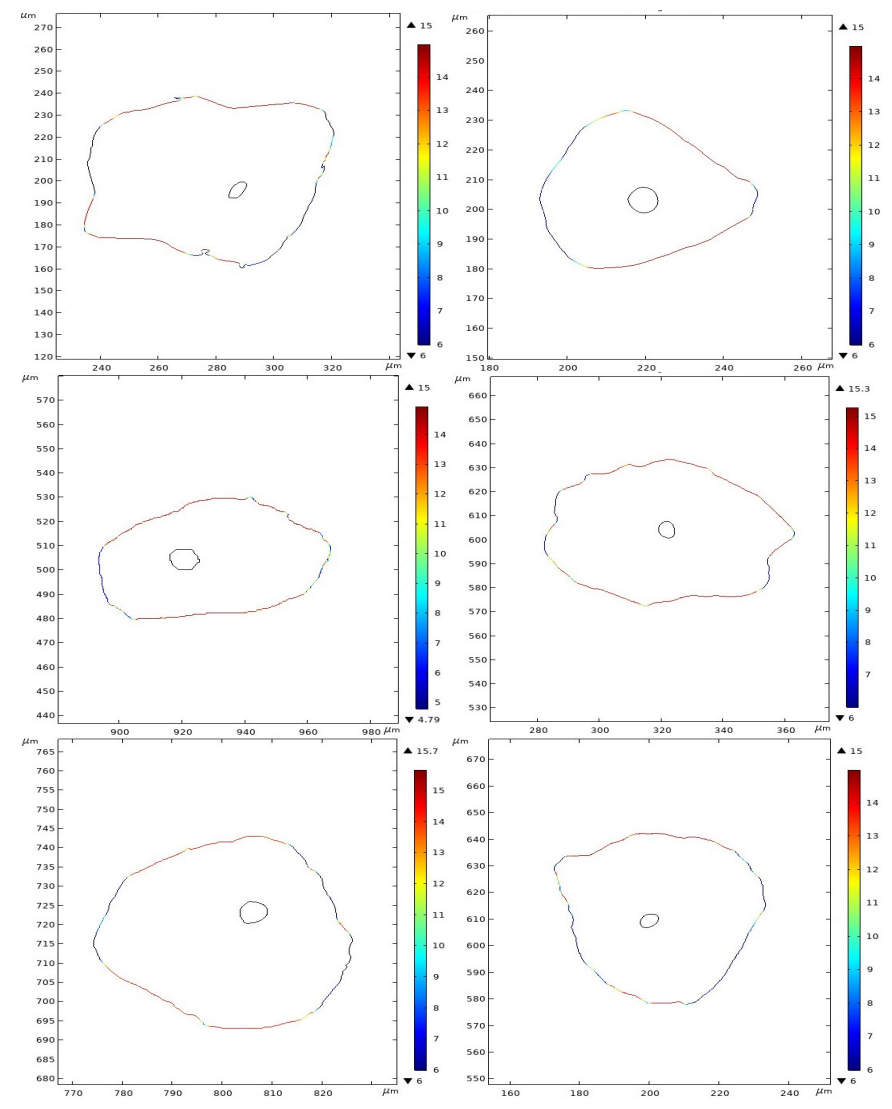

(a)

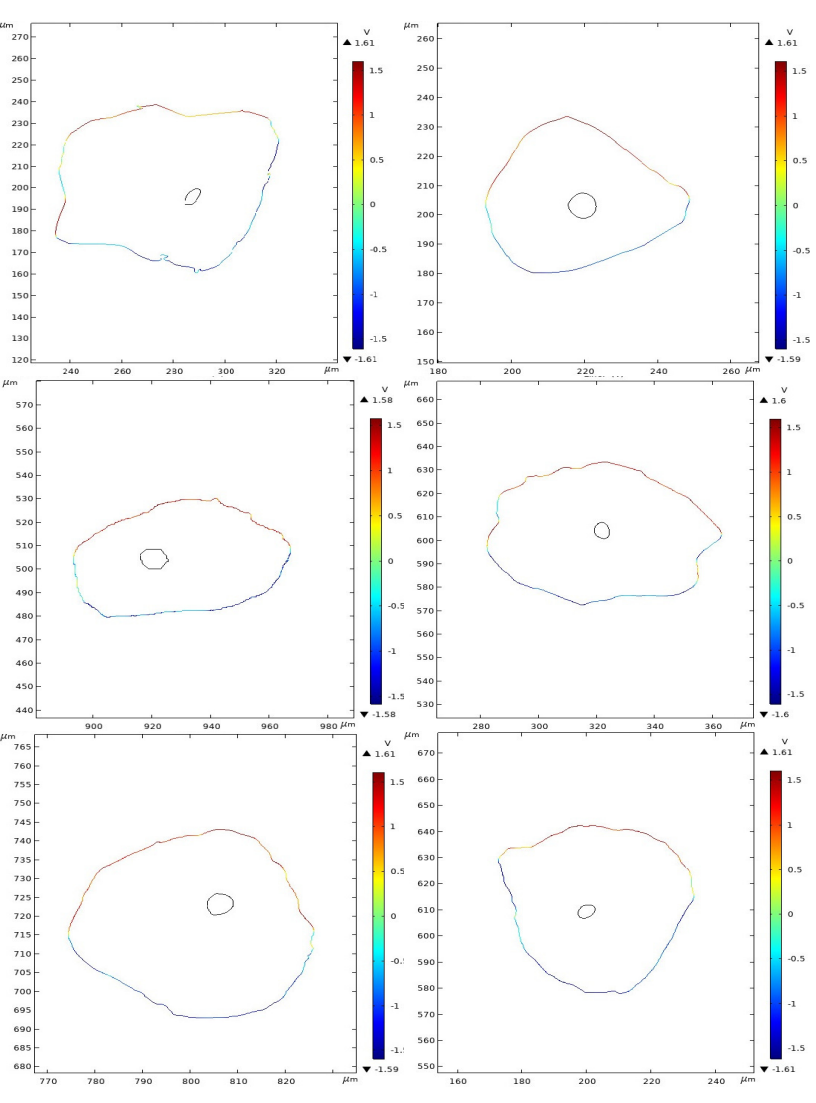

(b)

Figure 3. (a) Pore density $\left(\mathrm{m}^{-2}\right)$ at $20 \mathrm{~ns}$ in log-scale. (b) Transmembrane Voltage (V) at $20 \mathrm{~ns}$.

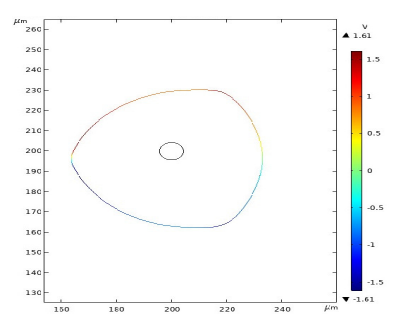

a)

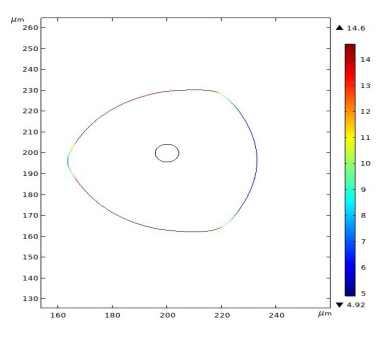

c)

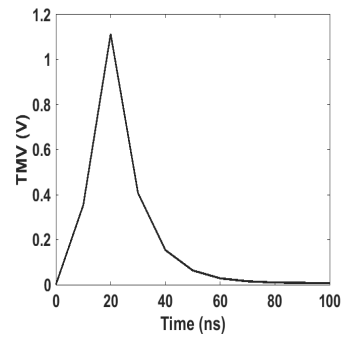

b)

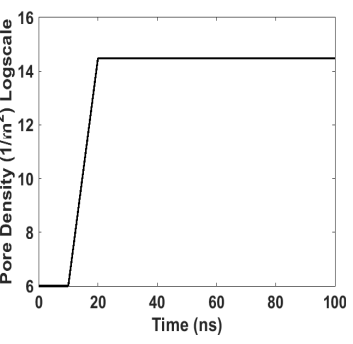

d)

Figure 4. Supergielis model superficial cervical cell results (a) Transmembrane potential (V) generated in the contour at time $20 \mathrm{~ns}$, (b) Transmembrane (V) plot of the parametric curve at $\theta=90$, (c) Pore density $\left(\mathrm{m}^{-2}\right)$ in log-scale of the parametric curve at time 20ns, d) Pore density $\left(\mathrm{m}^{-2}\right)$ plot in logscale at $\theta=90$. 


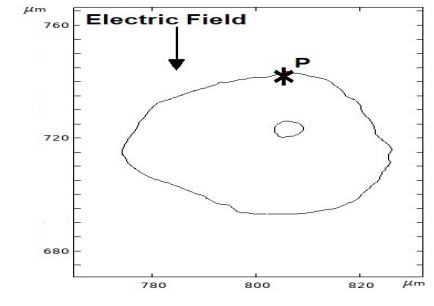

a)

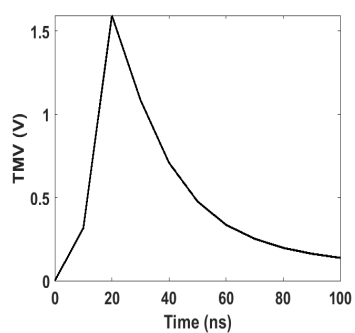

b)

(1)

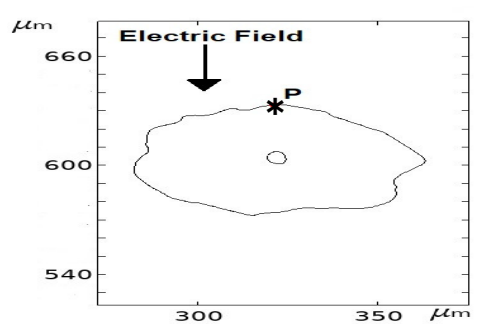

a)

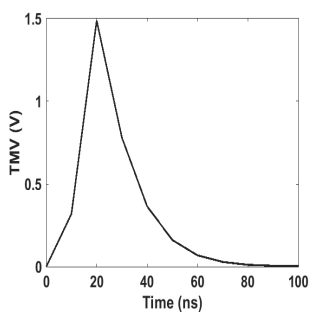

b)

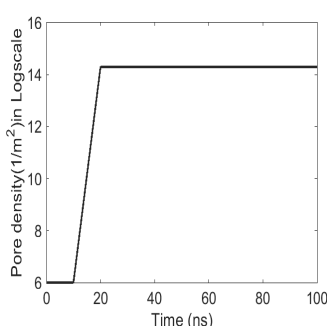

C)

(2)

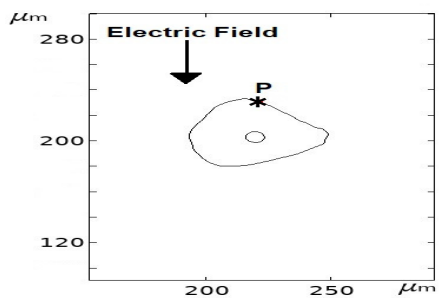

a)

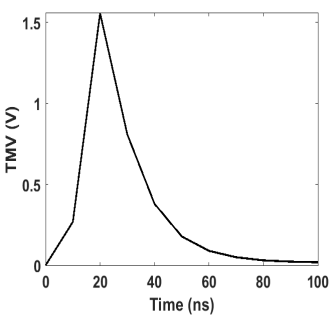

b)

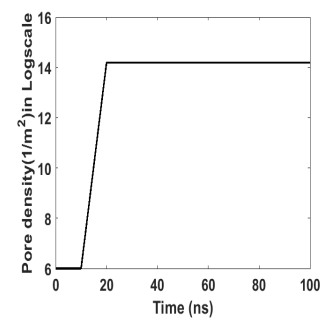

c)

Figure 5. (1) a) Intermediate cervical cell morphology , b) TMV (V) plot at point $\mathrm{P}$, c) Pore density $\left(\mathrm{m}^{-2}\right)$ in $\log$-scale at $\mathrm{P}$, (2) (a) Superficial cervical cell morphology , (b) TMV (V) plot at point P, c) Pore density $\left(m^{-2}\right)$ in log-scale at P, (3) Intermediate cell morphology, (b) TMV (V) plot at point P, c) Pore density $\left(m^{-2}\right)$ in log-scale at P. 
Table 2. Electroporation relative length of the respective cells

\begin{tabular}{|c|c|c|}
\hline Cellnumber & EPRL $(\%)$ & Type of cell \\
\hline 1$)$ & 41.67 & Intermediate cell \\
\hline 2$)$ & 53.43 & Intermediate cell \\
\hline 3$)$ & 63.22 & Superficial cell \\
\hline 4$)$ & 78.68 & Superficial cell \\
\hline 5$)$ & 63.22 & Intermediate cell \\
\hline 6$)$ & 31.25 & Superficial cell \\
\hline
\end{tabular}

to the electric field has also a considerable effect on the EPRL. The more the cell length directly exposed to the electric field larger is the EPRL for the cells. The Table 2 Shows all the EPRL generated of the cells given in the order Figure 1 where the EPRL is the area in which the pore density is in order $10^{14}$ or above. The cancer cell model is also extracted with help of image processing which is the first stage of cancer cell also known as the Cervical intraepithelial neoplasia (CIN1) stage of intermediate cell Figure 6 (a). The conductivity of cancer cells rises by a factor of 1.8 as stated in the literature survey ${ }^{15}$.This the maximum increment in the cervical cancer cell. The method proposed is to study the effect on the pore density due to a change in the conductivity of the cell. The Figure 6 (c) shows that as there is an increase in conductivity of the cell due to the cancer formation pore density increases when an electric field is applied. A concept of the Strength duration curve of the cells to plot and observe the threshold electric field and time required for pore formation is introduced in the literature ${ }^{29}$. The analysis in a similar way is done for normal and cancer cells by changing the conductivity by factor multiplication in steps (1.2, $1.5,1.8)$. The results are then analyzed by plotting them in the graph as shown in Figure 7 . It can be easily observed that the cancer cells require less amount of threshold electric field and duration as compared to the normal cells to electroporate.
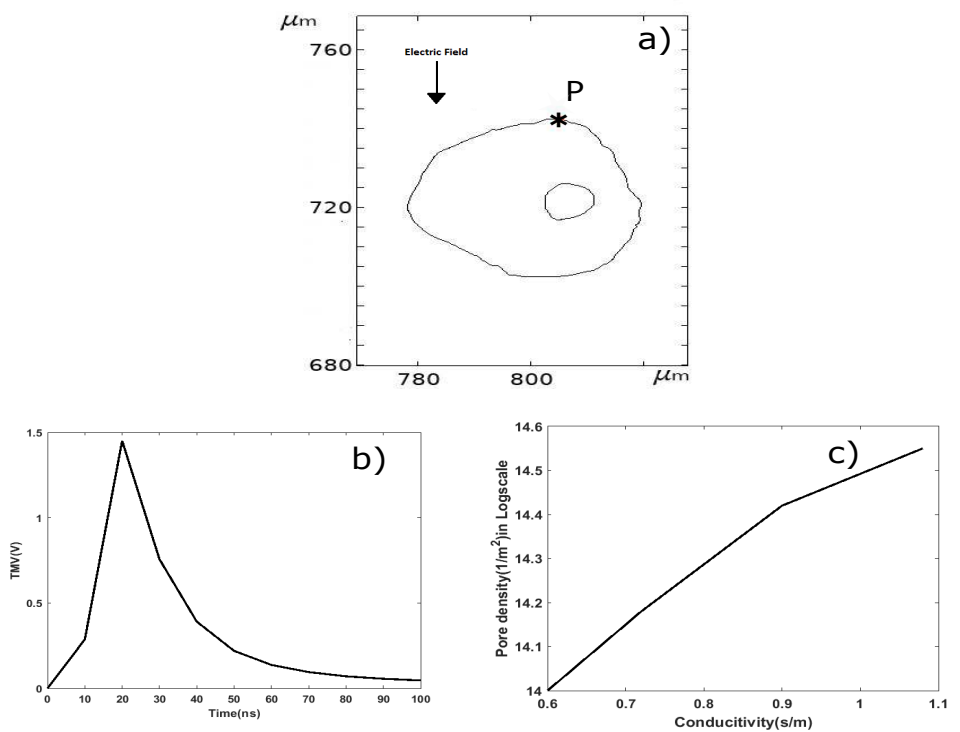

Figure 6. Temporal evaluation of cancer cell (a) Morphology of intermediate CIN1 stage cervical cell, (b) TMV plot of the cancer cell taken at given point $\mathrm{P}$, (c) Change in pore density $\left(\mathrm{m}^{-2}\right)$ at point $\mathrm{P}$ in log-scale due to conductivity change .

\section{Conclusion}

In this paper, the two-dimensional contour extraction of cervical cell images was performed using image processing techniques. The Marx pulse generator was built using avalanche transistor was used to generate a Gaussian pulse of nanoseconds duration. The hardware and simulation analysis has been done to demonstrate the working of the generator. The contour and the pulse generated were taken into the multiphysics area for a more realistic study of reversible electroporation. The dispersive cell medium and Smoluchowiski equation were used to generate the required Transmembrane potential produced on the cell membrane. The SuperGielis model was also implemented to reproduce the cervical cell model. The electroporation relative 


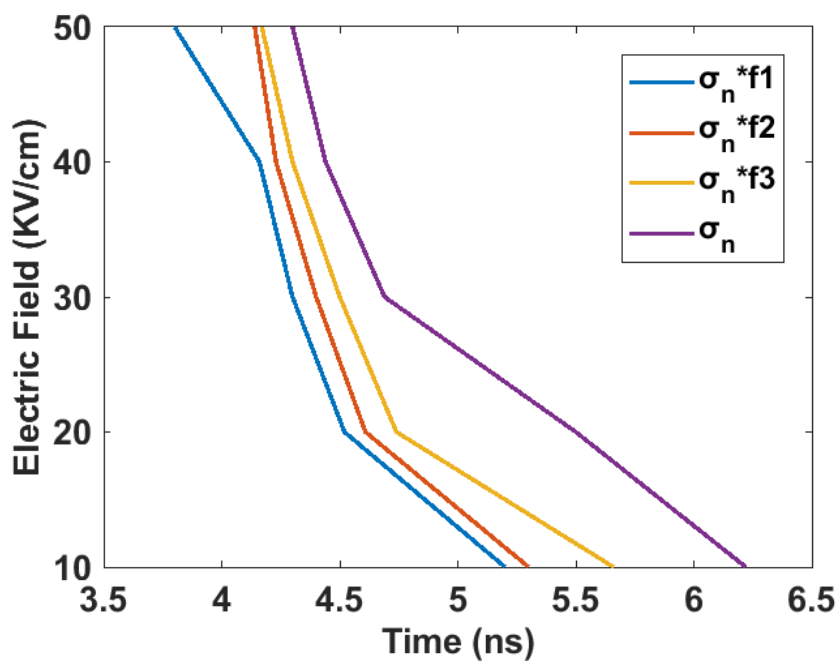

Figure 7. Strength-Duration curve where $\sigma_{n}$ represents conductivity $(\mathrm{S} / \mathrm{m})$ of normal intermediate cell and $\mathrm{f} 1=1.8, \mathrm{f} 2=1.5$, $\mathrm{f} 3=1.2$ are the factors by which the conductivity of cancer cell increases.

length (EPRL) was calculated to show the difference in the area of electroporation in the case of the parametric curve and the extracted contour. This model also used the dispersive medium to show the variation in the effects of reversible electroporation. This work was also used to extracted the morphology of the cervical cancer cell. The change in the conductivity of the cell due to the tumor formation was used to find the threshold electric field required to give reversible electroporation to the cell. The strength-duration plot is provided to demonstrate the difference in the electric field needed to electroporate the normal and the cancerous cervical cell. Thus, after a detailed analysis it was found that the cancer cells require less electric field and time to electroporate than the normal cells due to the conductivity increment as a result of a high content of sodium chloride in the cancer cell. Thus, the paper validates the hardware, addition of image processing techniques for microdosimetry analysis, change of conductivity in cancer cells and its effect on pore density when the electric field is applied and the threshold electric field of both normal and cancer cells. In future, multi-cellular cervical cells with both normal and cancer cells can be extracted and analyzed to get the idea of the electric field needed for electroporation of the cervical cells.

\section{References}

1. Ferlay J, Soerjomataram I, Dikshit R, Eser S, Mathers C, Rebelo M, Parkin DM, Forman D, Bray F. Cancer incidence and mortality worldwide: sources, methods and major patterns in GLOBOCAN 2012. Int J Cancer. 2015 Mar 1;136(5):E359-86. doi: 10.1002/ijc.29210. Epub 2014 Oct 9. PMID: 25220842.

2. Das L, Das S, Chatterjee J. Electrical Bioimpedance Analysis: A New Method in Cervical Cancer Screening. J Med Eng. 2015;2015:636075. doi: 10.1155/2015/636075. Epub 2015 Feb 2. PMID: 27006939; PMCID: PMC4782745.

3. Potter H. Electroporation in biology: methods, applications, and instrumentation. Anal Biochem. 1988 Nov 1;174(2):361-73. doi: 10.1016/0003-2697(88)90035-8. PMID: 3071177.

4. Krassowska W, Filev PD. Modeling electroporation in a single cell. Biophys J. 2007 Jan 15;92(2):404-17. doi: 10.1529/biophysj.106.094235. Epub 2006 Oct 20. PMID: 17056739; PMCID: PMC1751390.

5. E. Salimi, D. J. Thomson and G. E. Bridges, "Membrane dielectric dispersion in nanosecond pulsed electroporation of biological cells," in IEEE Transactions on Dielectrics and Electrical Insulation, vol. 20, no. 4, pp. 1256-1265, August 2013, doi: 10.1109/TDEI.2013.6571442.

6. Pucihar G, Miklavcic D, Kotnik T. A time-dependent numerical model of transmembrane voltage inducement and electroporation of irregularly shaped cells. IEEE Trans Biomed Eng. 2009 May;56(5):1491-501. doi: 10.1109/TBME.2009.2014244. Epub 2009 Feb 6. PMID: 19203876.

7. Chiapperino MA, Bia P, Caratelli D, Gielis J, Mescia L, Dermol-Černe J, Miklavčič D. Nonlinear Dispersive Model of Electroporation for Irregular Nucleated Cells. Bioelectromagnetics. 2019 Jul;40(5):331-342. doi: 10.1002/bem.22197. Epub 2019 Jun 9. PMID: 31179573.

8. Miklavcic D, Puc M (2006) Electroporation, Wiley Encyclopedia of Biomedical Engineering. John Wiley, Newyork 
9. C. Merla, A. Paffi, F. Apollonio, P. Leveque, G. d'Inzeo and M. Liberti, "Microdosimetry for Nanosecond Pulsed Electric Field Applications: A Parametric Study for a Single Cell," in IEEE Transactions on Biomedical Engineering, vol. 58, no. 5, pp. 1294-1302, May 2011, doi: 10.1109/TBME.2010.2104150.

10. Denzi A, Camera F, Merla C, Benassi B, Consales C, Paffi A, Apollonio F, Liberti M. A Microdosimetric Study of Electropulsation on Multiple Realistically Shaped Cells: Effect of Neighbours. J Membr Biol. 2016 Oct;249(5):691-701. doi: 10.1007/s00232-016-9912-3. Epub 2016 Jun 18. PMID: 27318672.

11. L. Mescia, M. A. Chiapperino, P. Bia, J. Gielis and D. Caratelli, "Modeling of Electroporation Induced by Pulsed Electric Fields in Irregularly Shaped Cells," in IEEE Transactions on Biomedical Engineering, vol. 65, no. 2, pp. 414-423, Feb. 2018, doi: 10.1109/TBME.2017.2771943.

12. M. A. Chiapperino et al., "Experimental and Numerical Study of Electroporation Induced by Long Monopolar and Short Bipolar Pulses on Realistic 3D Irregularly Shaped Cells," in IEEE Transactions on Biomedical Engineering, vol. 67, no. 10, pp. 2781-2788, Oct. 2020, doi: 10.1109/TBME.2020.2971138.

13. D.C. Walker; B.H. Brown; D.R. Hose; R.H. Smallwood,"Modelling the electrical impedivity of normal and premalignant cervical tissue", Electronics Letters ( Volume: 36, Issue: 19, 14 Sep 2000)

14. D C Walker 1, B H Brown, R H Smallwood, D R Hose, D M Jones,"Modelled current distribution in cervical squamous tissue",Physiol Meas . 2002 Feb;23(1):159-68. doi: 10.1088/0967-3334/23/1/315.

15. Yongji Yang,Michael A. J. Moser,Edwin Zhang,Wenjun Zhang ,Bing Zhang ,"Development of a statistical model for cervical cancer cell death with irreversible electroporation in vitro",Published: April 25, 2018https://doi.org/10.1371/journal.pone.0195561

16. Balidemaj E, de Boer P, van Lier AL, Remis RF, Stalpers LJ, Westerveld GH, Nederveen AJ, van den Berg CA, Crezee J. In vivo electric conductivity of cervical cancer patients based on B maps at 3T MRI. Phys Med Biol. 2016 Feb 21;61(4):1596-607. doi: 10.1088/0031-9155/61/4/1596. Epub 2016 Feb 2. PMID: 26836010.

17. M. Al Ahmad, Z. Al Natour, F. Mustafa and T. A. Rizvi, "Electrical Characterization of Normal and Cancer Cells," in IEEE Access, vol. 6, pp. 25979-25986, 2018, doi: 10.1109/ACCESS.2018.2830883.

18. http://mde-lab.aegean.gr/index.php/downloads

19. I. Cameron, N. K. Smith, T. B. Pool, and R. L. Sparks, "Intracellularconcentration of sodium and other elements as related to mitogenesis and oncogenesis in vivo," Cancer Res., vol. 40, no. 5, pp. 1493-1500,May 1980

20. Gonzalez RC, Woods RE (2002) Digital image processing. Prentice Hall Upper Saddle River, New Jersey

21. Amitabh Chatterjee, Kanad Mallik, and S. M. Oak,"The principle of operation of the avalanche transistor-based Marx bank circuit: A new perspective",Review of Scientific Instruments 69, 2166 (1998).

22. M. R. Tajik and A. R. Nateghi, "Design, Simulation and Performance Comparison of Pulse Power Generator based on the Avalanche Breakdown Phenomenon in Bipolar Junction Transistors," 2020 11th Power Electronics, Drive Systems, and Technologies Conference (PEDSTC), Tehran, Iran, 2020, pp. 1-6, doi: 10.1109/PEDSTC49159.2020.9088479.

23. K. Opalska and L. J. Opalski, "A model of the BJT Avalanche Breakdown for Circuit Simulation," in Proc. of the European Conference on Circuit Theory and Design (ECCTD'1997), 1997, pp. 220-225.

24. C. Li et al., "Design and Development of a Compact All-Solid-State High-Frequency Picosecond-Pulse Generator," in IEEE Transactions on Plasma Science, vol. 46, no. 10, pp. 3249-3256, Oct. 2018, doi: 10.1109/TPS.2018.2850153.

25. Z. Li, P. Li, J. Rao, S. Jiang and T. Sakugawa, "Theoretical Analysis and Improvement on Pulse Generator Using BJTs as Switches," in IEEE Transactions on Plasma Science, vol. 44, no. 10, pp. 2053-2059, Oct. 2016, doi: 10.1109/TPS.2016.2604407.

26. Denzi A, Merla C, Camilleri P, Paffi A, d'Inzeo G, Apollonio F, Liberti M. 2013. Microdosimetric study for nanosecond pulsed electric fields on a cell circuit model with nucleus. J Membr Biol 246:761-767.

27. Kotnik T, Rems L, Tarek M, Miklavčič D. 2019. Membrane electroporation and electropermeabilization: mechanisms and models. Ann Rew Biophys 48:63-91

28. De Angelis Annalisa, Denzi Agnese, Merla Caterina, Andre Frank M., Mir Lluis M., Apollonio Francesca, Liberti Micaela,"Confocal Microscopy Improves 3D Microdosimetry Applied to Nanoporation Experiments Targeting Endoplasmic Reticulum ",Frontiers in Bioengineering and Biotechnology ,10.3389/fbioe.2020.552261

29. Joshi RP, Mishra A, Schoenbach KH (2008) Model assessment of cell membrane breakdown in clusters and tissues under highintensity electric pulsing. IEEE Trans Plasm Sci 36:1680-1688 


\section{Figures}

a) Cervical cell

1)

2)

3)

4)

5)

6)

) b) Denoisied image c) Clustered image

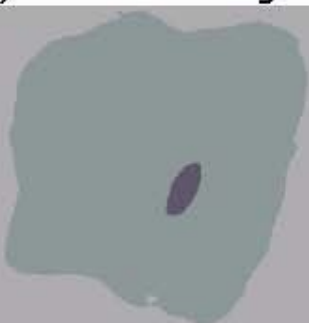

dge detection
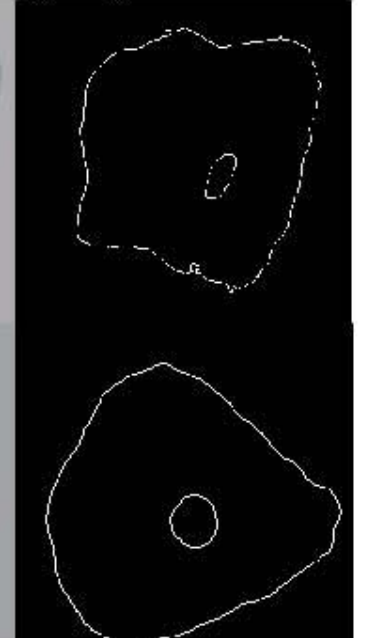
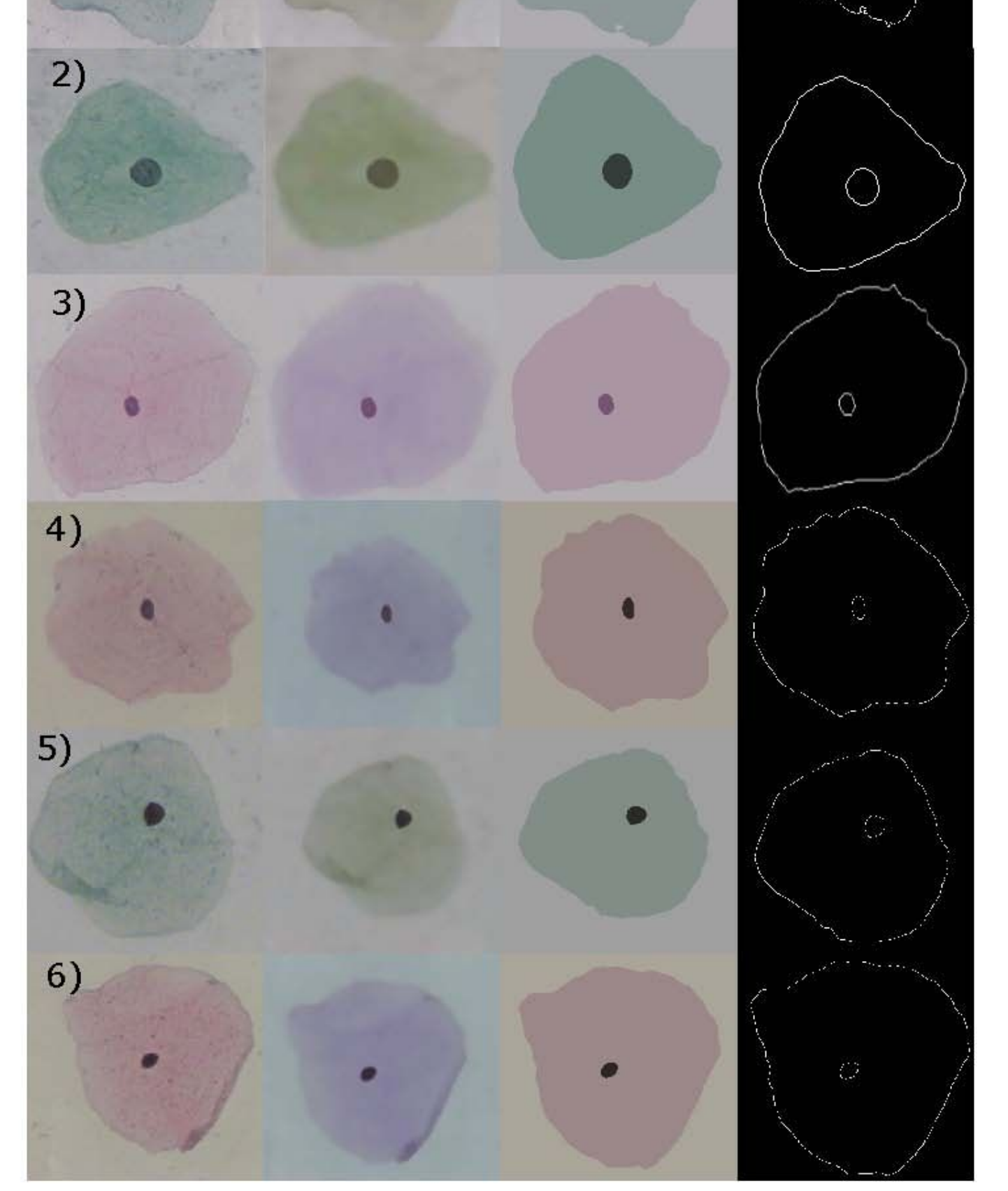

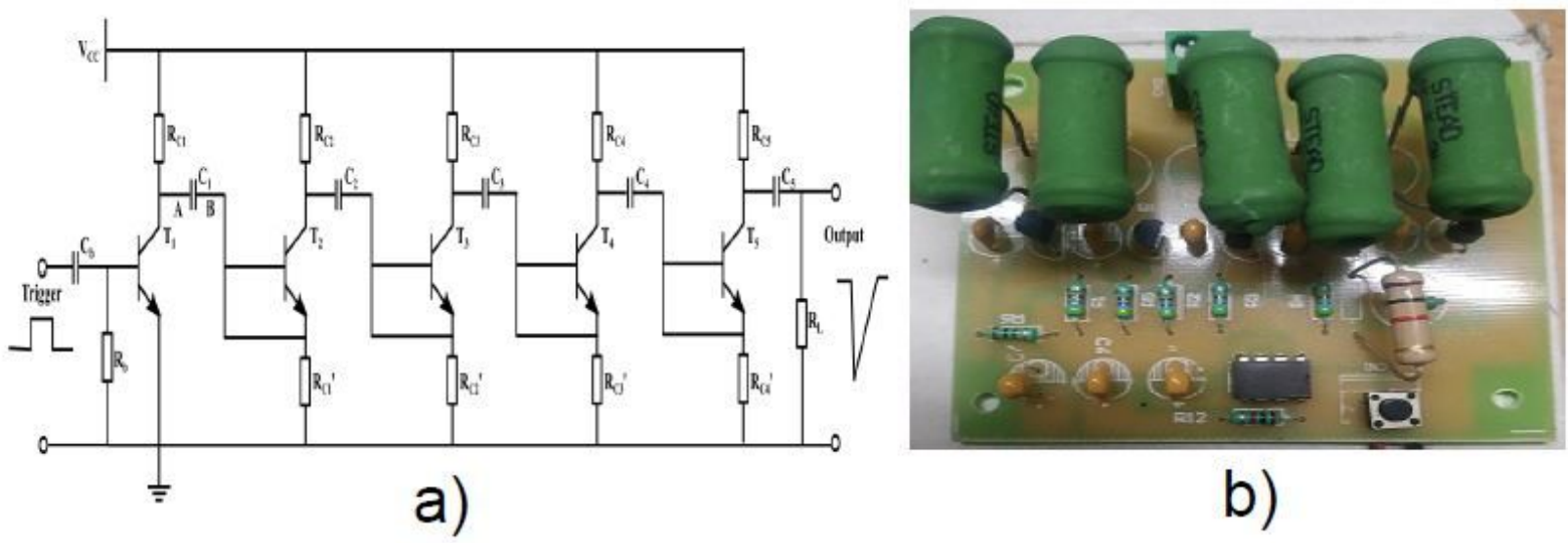

b)
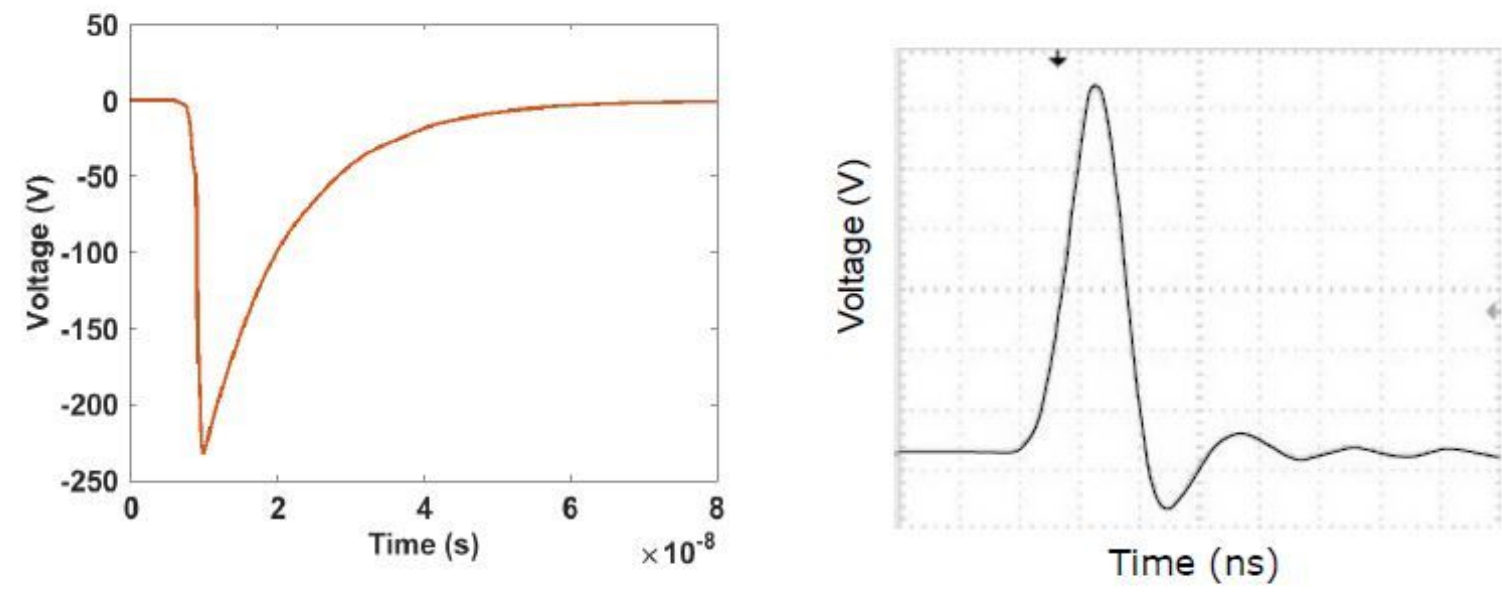

c)

d)

Figure 2

a) Marx Generator schematic diagram25, b) Pulse generator hardware, (c) Simulated output of the Marx generator, (d) Output waveform time $X=20 \mathrm{~ns} /$ div and voltage $Y=5 \mathrm{~V} / \mathrm{div}$. 


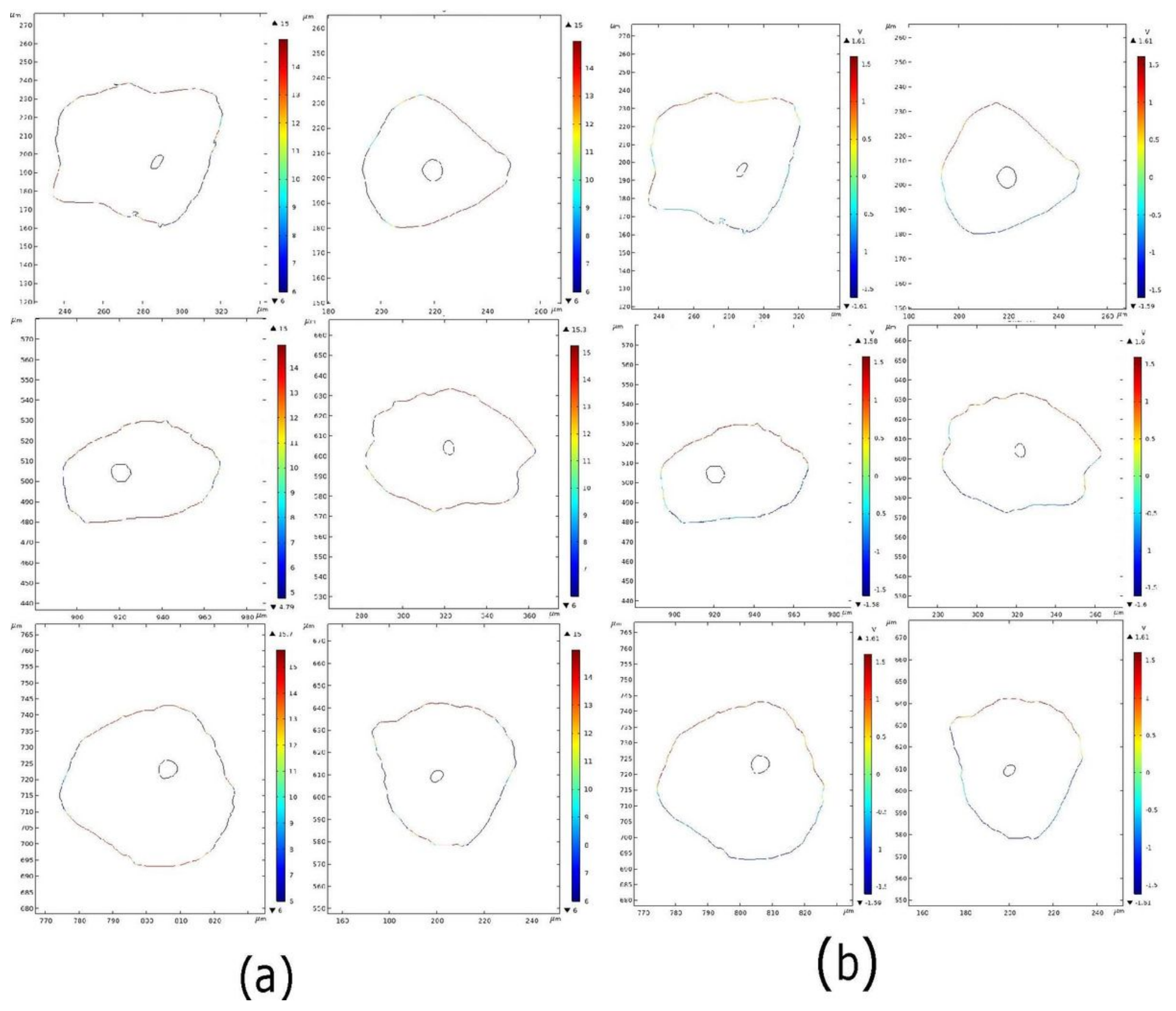

Figure 3

(a) Pore density (m-2) at $20 \mathrm{~ns}$ in log-scale. (b) Transmembrane Voltage (V) at $20 \mathrm{~ns}$. a) 


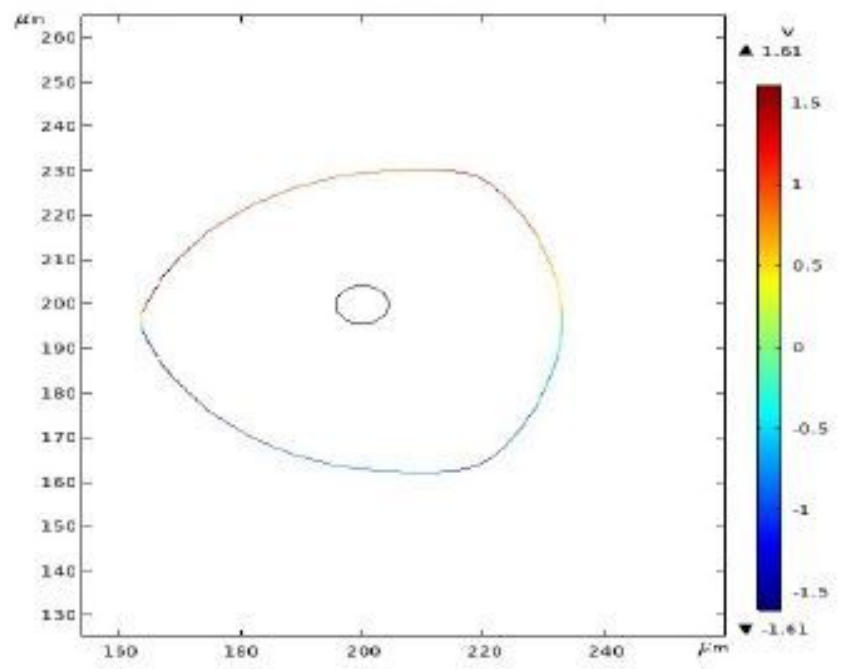

a)

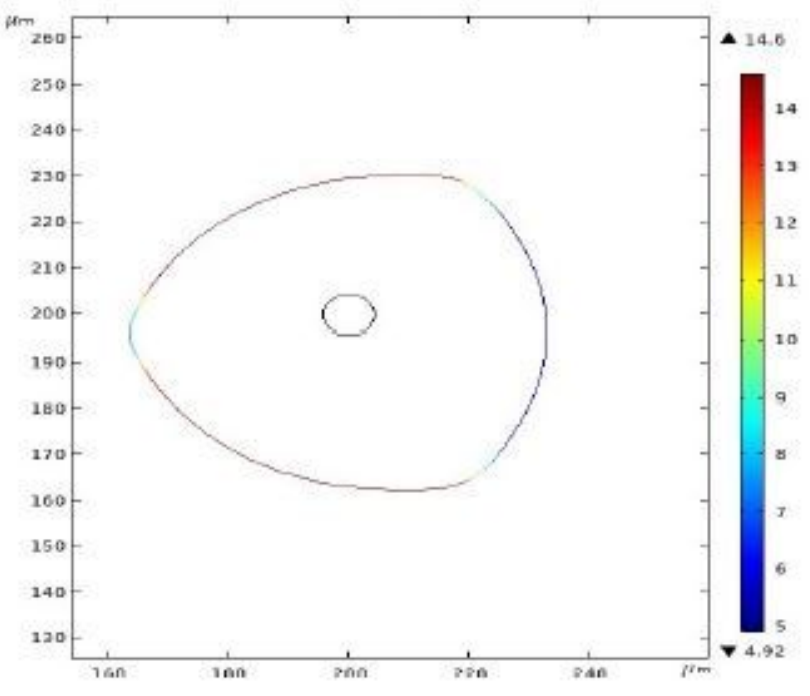

c)

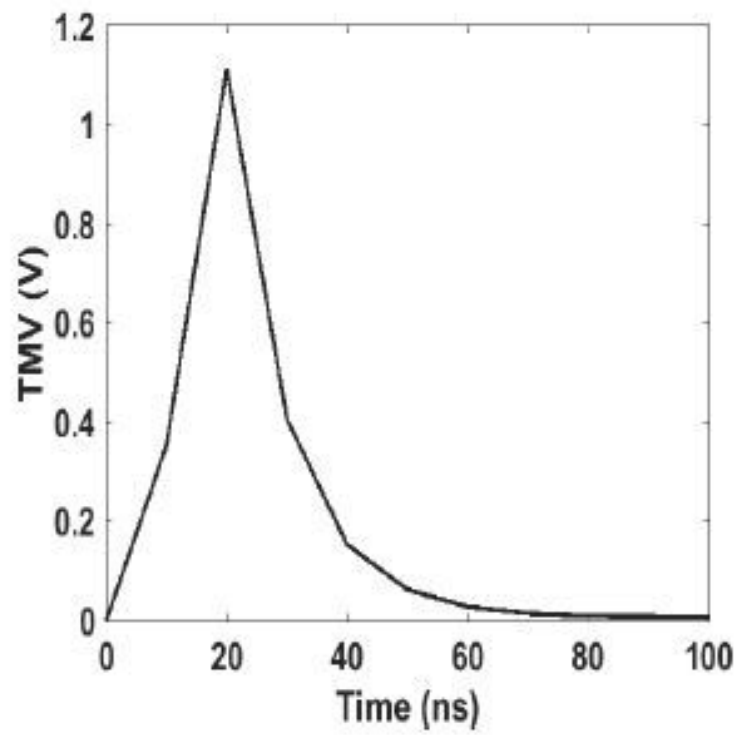

b)

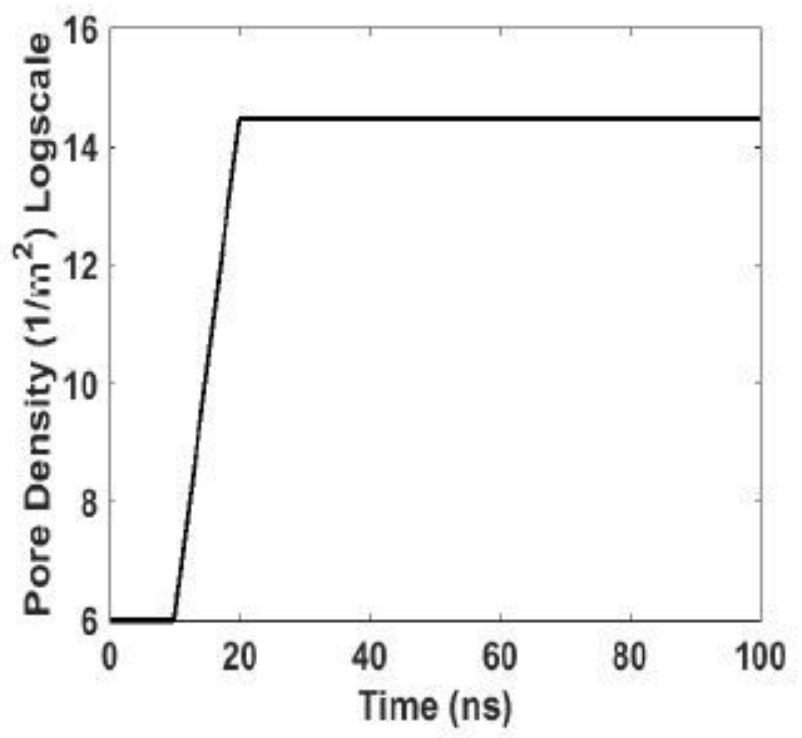

d)

\section{Figure 4}

Supergielis model superficial cervical cell results (a) Transmembrane potential (V) generated in the contour at time 20ns, (b) Transmembrane (V) plot of the parametric curve at $\theta=90$, (c) Pore density ( $m-2$ ) in log-scale of the parametric curve at time 20ns, d) Pore density $(m-2)$ plot in logscale at $\theta=90$. 


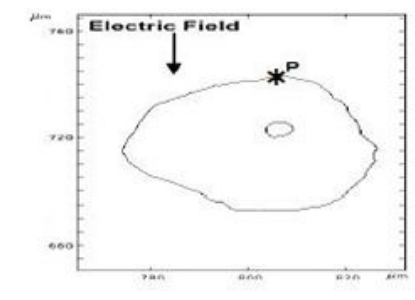

a)

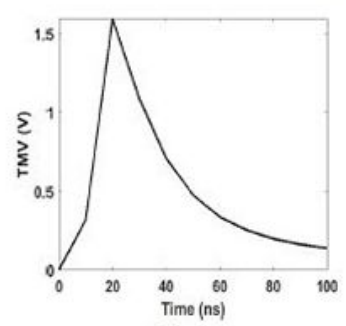

b)

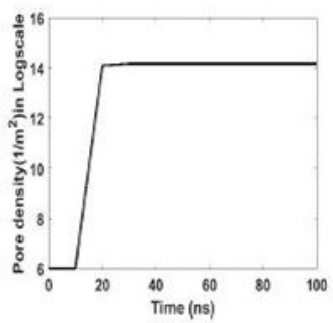

c)

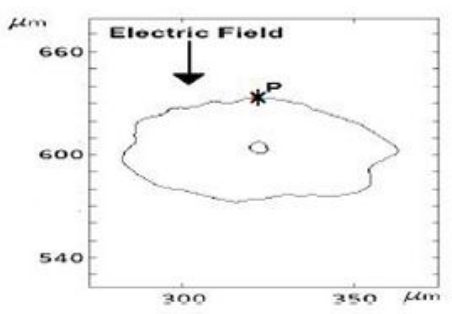

a)

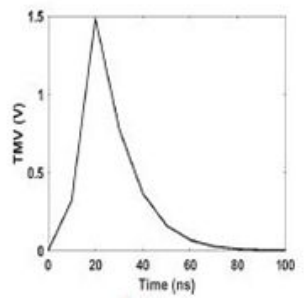

b)

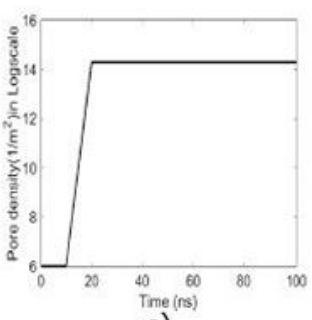

c)

(1)

(2)

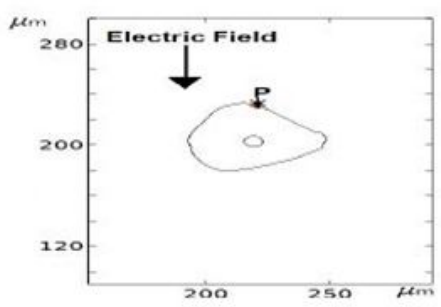

a)

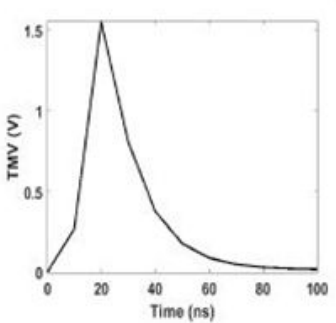

b)

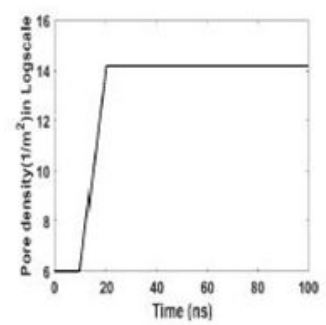

c)

(3)

\section{Figure 5}

(1) a) Intermediate cervical cell morphology , b) TMV (V) plot at point P, c) Pore density (m-2) in log-scale at $\mathrm{P},(2)(\mathrm{a})$ Superficial cervical cell morphology , (b) TMV (V) plot at point $\mathrm{P}, \mathrm{c})$ Pore density $(\mathrm{m}-2)$ in logscale at $P,(3)$ Intermediate cell morphology, (b) TMV (V) plot at point $P, c)$ Pore density $(m-2)$ in log-scale at $\mathrm{P}$. 

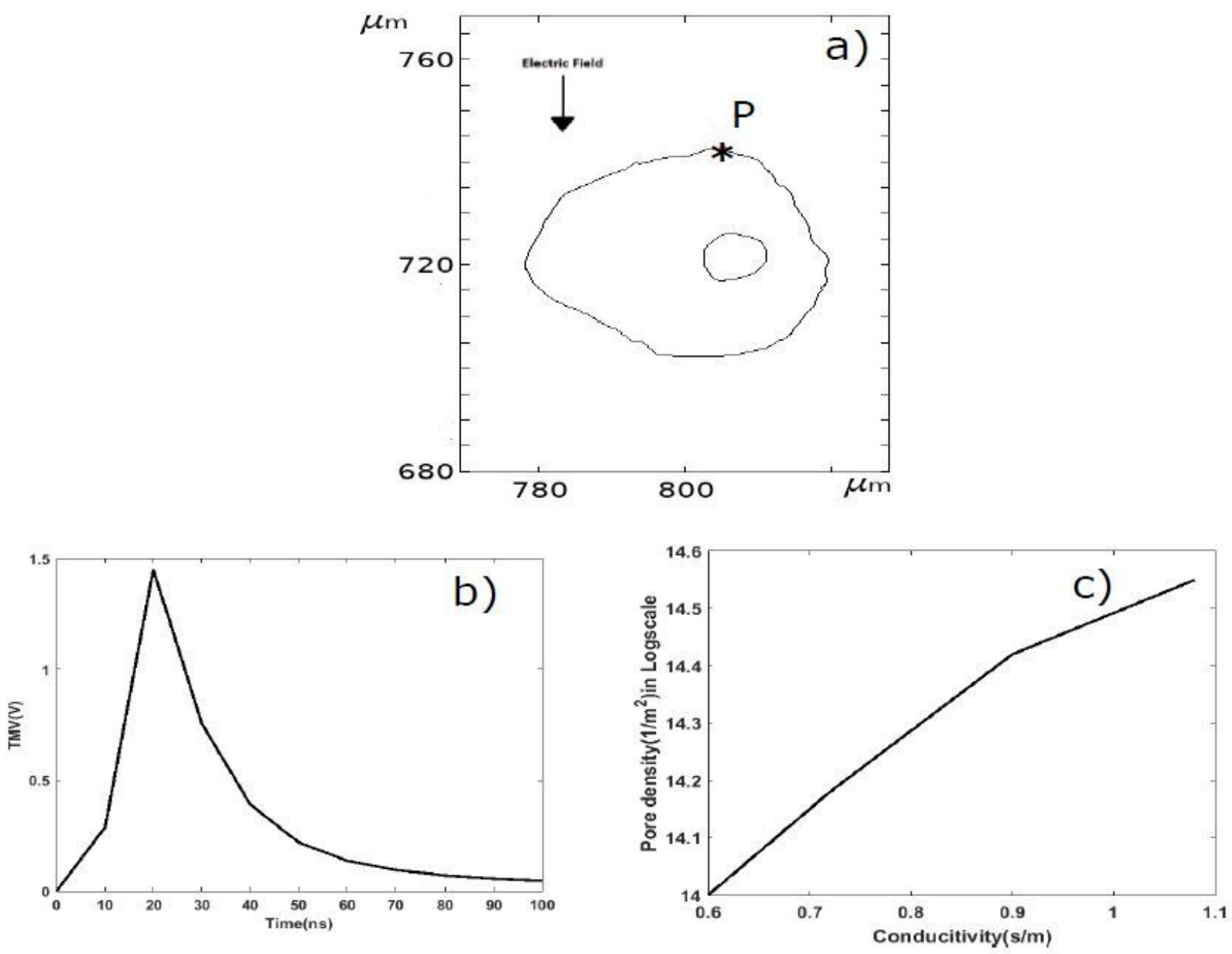

Figure 6

Temporal evaluation of cancer cell (a) Morphology of intermediate CIN1 stage cervical cell, (b) TMV plot of the cancer cell taken at given point $\mathrm{P},(\mathrm{c})$ Change in pore density $(\mathrm{m}-2)$ at point $\mathrm{P}$ in log-scale due to conductivity change. 


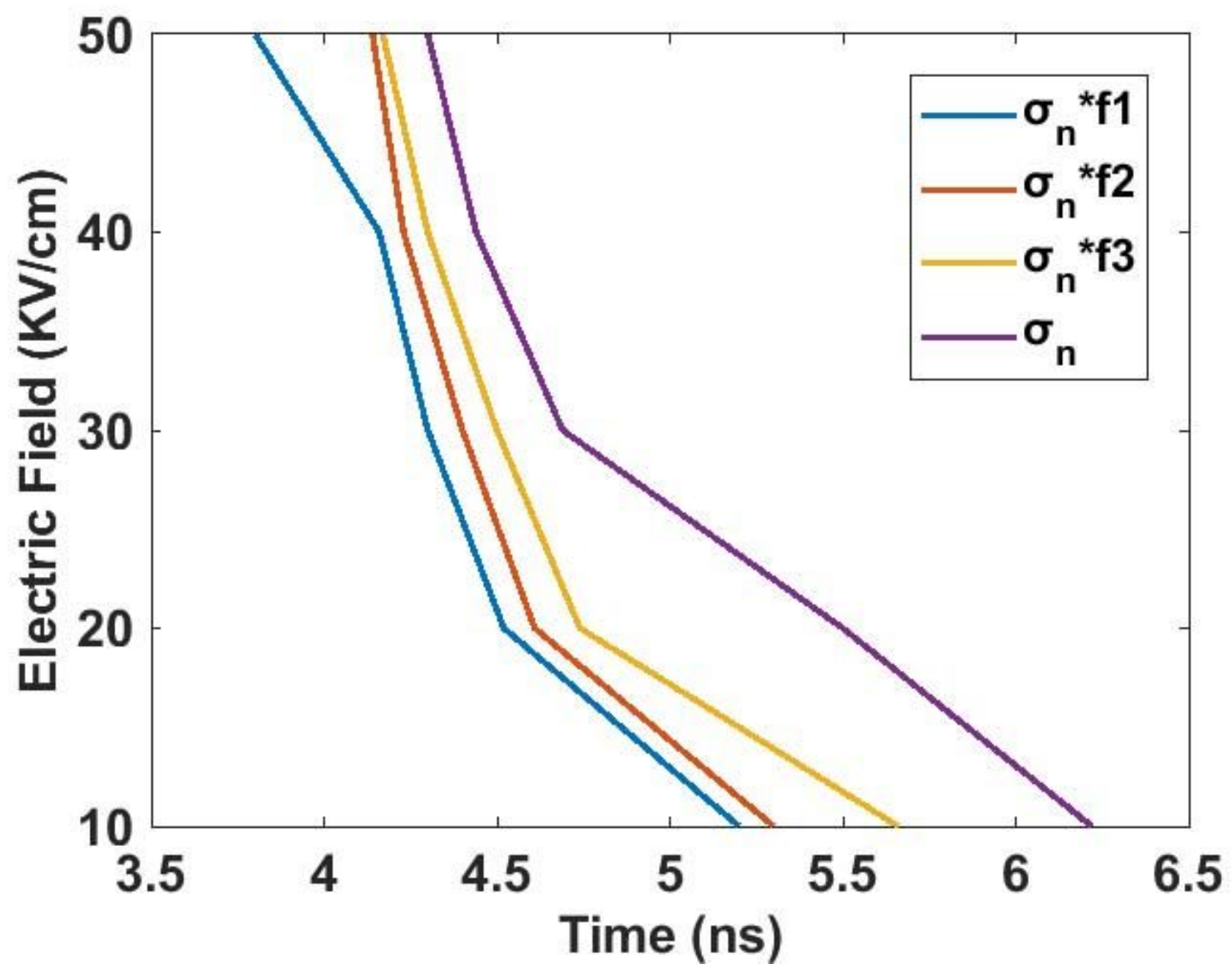

Figure 7

Strength-Duration curve where $\sigma$ represents conductivity $(\mathrm{S} / \mathrm{m})$ of normal intermediate cell and $\mathrm{f} 1=1.8$, $\mathrm{f} 2=1.5, \mathrm{f} 3=1.2$ are the factors by which the conductivity of cancer cell increases. 